\title{
Influence of hypophysectomy, ovariectomy and gonadectomy on postoperative hypersensitivity in rats
}

\author{
Dustin P. Green ${ }^{2}$, Mayur J. Patil ${ }^{1}$ and Armen N. Akopian ${ }^{1,3 *}$ \\ ${ }^{1}$ Department of Pharmacology, UT Health Science Center, San Antonio, TX, USA \\ ${ }^{2}$ Department of Neuroscience, Johns Hopkins University, School of Medicine, Baltimore, USA \\ ${ }^{3}$ Department ofEndodontics, UT Health Science Center, San Antonio, TX, USA
}

\begin{abstract}
Surgical procedures lead to profound and sustained (up to 1-2 weeks) activation of the pituitary gland, resulting in changes in endocrine function. Questions remain on whether activation of the pituitary influences the threshold and development time-course of postoperative pain. To address these questions, we evaluated postoperative hypersensitivity in female and male rats with ablated pituitary and gonadal hormone productions via hypophysectomy, ovariectomy and gonadectomy, respectively. Plantar incision, a model of acute postoperative pain, or sham operation was performed on rat hindpaws. Hypophysectomy, ovariectomy and gonadectomy were achieved by surgical disconnection of pituitary, ovaries and testicles, respectively. Postoperative thermal and mechanical hypersensitivity were monitored for 7 days post incision. Hypophysectomy on female and male rats produced statistically similar thermal and mechanical postoperative hypersensitivity thresholds and time-courses as compared to intact estrous female and male rats. Moreover, ovariectomy and gonadectomy did not significantly change postoperative hypersensitivity observed in control female and male animals. Our experiments demonstrate that hypophysectomy, ovariectomy and gonadectomy do not significantly impact postoperative hypersensitivity observed in normal female and male animals. These data suggest that surgery-induced changes in the endocrine system via activation of pituitary and subsequently gonadal tissues have little impact on the threshold and development of postoperative pain in female and male rats.
\end{abstract}

\section{Introduction}

It is well documented that surgical intervention profoundly modulates the endocrine system leading to complex metabolic events [1-3]. Tissue injury and psychological stress associated with surgeries and/or anesthetics used during surgical procedures could be major contributors in modulating the endocrine system [4]. There is evidence that the response of the endocrine system to surgical intervention is mediated through the hypothalamic-pituitary-adrenal (HPA) axis [5]. Thus, major and some minor surgeries usually result in systemic sustained increase of adrenocorticotropin (ACTH), growth hormone $(\mathrm{GH})$ and prolactin (PRL), whereas plasma estradiol and testosterone levels are decreased for up to 1-2 weeks after surgery [1,6-8]. The magnitude of HPA responses vary depending on type and the extent of surgery, as well as patients' sex and age [5,7,9-12].

Plasma levels of some hormones correlate with severity of postoperative pain $[13,14]$. A severe catabolic state driven by a prolonged endocrine reaction to surgery may be linked with an increased morbidity and mortality in high-risk adult patients [2]. Further, successful management of postoperative pain restores the normal serum levels of these hormones $[10,13]$. Systemic elevation of hormones after surgery could stimulate the immune system $[9,15,16]$, which plays a critical role in regulating pain development and threshold [17].

Despite the wealth of data on modulation of the endocrine system by surgical intervention, an important important question remains unanswered. Do pituitary and gonad-produced hormones directly impact the threshold and development of postoperative pain? This critical information could provide major clinical benefits in the diagnosis as well as the management of postoperative in patients undergoing surgical procedures and stress. Here, we will address the question of whether pituitary and gonad-produced hormones contribute to postoperative pain. Pituitary and gonadal hormone productions will be stopped via hypophysectomy (HYPO) in females and males, ovariectomy (OVX) in females and gonadectomy (GDX) in males,respectively. Plantar incision on rat hindpaws will be used as a model to study acute postoperative pain. This rodent surgery closely models surgical effects on the endocrine system in humans, leading to elevation of plasma levels for ACTH [18], GH [19] and PRL [20], as well as reduction in gonadal hormones [21,22].

\section{Materials and methods}

\section{Animals, hypophysectomy, ovariectomy and gonadectomy}

All animal experiments conformed to APS's Guiding Principles in the Care and Use of Vertebrate Animals in Research and Training, and to protocols approved by the University Texas Health Science Center at San Antonio (UTHSCSA) Animal Care and Use Committee (IACUC). We also followed guidelines issued by the National Institutes of Health and the Society for Neuroscience to minimize the number of animals used and their suffering.

Intact and operated adult female and male Sprague-Dawley rats

Correspondence to: Armen N. Akopian, Department of Endodontics, School of DentistrySchool, UTHSCSA, San Antonio, TX, USA, Tel: 210-567-3193; Fax: 210-567-3389; E-mail: akopian@uthscsa.edu

Key words: hypophysectomy, ovariectomy, surgical procedure, pain

Received: April 18, 2016; Accepted: May 16, 2016; Published: May 20, 2016 
(200-250g, Charles River Laboratories, Wilmington, MA) were housed three per cage under a 12-h light/12-h dark cycle with food and water available ad libitum. Additionally, hypophysectomized animals received water containing $5 \%$ dextrose and $0.9 \% \mathrm{NaCI}$. Adult female and male HYPO, OVX female and GDX male rats were obtained from Charles River Laboratories (Wilmington, MA). Hypophysectomy, ovariectomy and gonadectomy are achieved by surgical disconnection or removal of pituitary, ovaries and testis, respectively. Gonadal hormones in serum were measured using $17 \beta$-estradiol high sensitivity and testosterone ELISA kits (both ENZO). PRL serum levels were measured as previously described using rat Prolactin ELISA kit (Cayman Chemical) [20].

\section{Acute postoperative pain model}

All behavioral experiments were conducted by a blinded observer. Since HYPO and OVX female rats have no regular estrous cycles, surgical procedures on these female rats wereconducted without taking into account the estrus phase. The reproductive stage of cycling intact females was determined by vaginal lavage using methods previously described [23]. The plantar incisions in rats were performed as previously described [24]. Briefly, rats were anesthetized using $2 \%$ isoflurane. The right hindpaw was prepared for incision by application of antiseptic betadine solution. The incision model in rats was created by a $1-\mathrm{cm}$ longitudinal incision, through skin and fascia of the plantar aspect of the foot, beginning $0.5 \mathrm{~cm}$ from the proximal edge of the heel and extending toward the toes. Curved forceps were used to elevate longitudinally the underlying the plantaris muscle. A mattress suture of 5-0 nylon on a FS-2 needle (Ethicon, Somerville, NJ) was used to close the incision. Antibiotic neomycin ointment (Bacitracin Zinc Ointment USP, Melville, NY) was applied to the wound and the sutures removed 2 days later. Sham treatment consisted of rats that received anesthesia, antiseptic preparation and topical antibiotic without an incision. Thermal and mechanical hypersensitivity were measured in these animals over a period of 7 days.

\section{Thermal hypersensitivity}

Rats were habituated to the testing environment for at least $30 \mathrm{~min}$ prior to testing. Heat nociception was assessed as previously described [25]. In brief, rats were placed on a glass surface with temperature held constant at $\approx 20^{\circ} \mathrm{C}$. Following habituation, thermal withdrawal latencies to a radiant heat beam focused on the plantar area of the hindpaw were recorded at each time point (3X measurements at each time point, averaged to obtain the data value used in analyses). In order to prevent tissue damage, the stimulus was terminated after $\approx 20 \mathrm{sec}$ if the animal did not withdraw the hind paw.

\section{Mechanical hypersensitivity}

After habituation to the testing environment, the baseline readings (three readings per animal) were taken on the right hind paw using the Dynamic Plantar Aesthesiometer (UgoBasile) to record withdrawal thresholds for mechanical stimulation of the plantar area of the hindpaw. Theinstrument applies constant ramp of increasing mechanical pressure to the paw (from 0 to 50 grams over 10 second intervals) and the withdrawal threshold was recorded in grams when the paw was withdrawn.

\section{Data analyses}

GraphPad Prism 5.0 (GraphPad, La Jolla, CA) was used for statistical analyses. The data in Figures were given as mean \pm standard error of the mean (SEM), with the value of " $n$ " referring to the number of analyzed animals for each group. All experiments were performed in duplicate with the use of a different set of rats. Differences between groups were assessed by two-way analysis of variance (ANOVA; no matching, regular 2-way ANOVA, not repeated measures) with Bonferroni's multiple comparison post-hoc tests (where each column was compared to all other columns). Differences between male and female post-operative hyperelgesia were conducted with 3-way ANOVA with sex, rat line (i.e.,hypophysectomized, ovariectomized or gonadectomized) and time as factors. A difference was accepted as statistically significant when $\mathrm{p}<0.05$.

\section{Results}

\section{Hypophysectomy and postoperative hypersensitivity}

HYPO leads to substantial reduction of serum PRL levels in females $(\approx 7$ fold) and moderate decrease in males $(\approx 2$ fold) (Table 1$)$. It was suggested that remaining PRL in serum could be attributed to extrapituitary origin [26-29]. As expected [30, 31], HYPO, which leads to substantial decrease of luteinizing hormones (LH) and to a lesser extent follicle stimulating hormone (FSH) [32, 33], reduced serum estradiol levels (Table 1). Basal levels (BL) of thermal (heat) nociception are not statistically different in HYPO versus intact (Int) male and female rats (Figure 1A and 1B). This is in accordance with previously published data [34]. Incision-induced thermal hypersensitivity was similar for HYPO compared to intact females (in estrous phase) atall tested postsurgery time points (Figure 1A). HYPO did not significantly change postoperative thermal hypersensitivity at 1,3 and 7 days post-surgery for male rats (Figure 1B). Like intact females and males, HYPO females and males exhibited statistically comparable levels and development time-course of postoperative thermal hypersensitivity. Thus, thermal hypersensitivity for HYPO and intact rats of both sexes was resolved by 7 days post-incision.

We next evaluated whether postoperative mechanical hypersensitivity was altered in male and female rats that have undergone hypophysectomy. Basal (BL) behavioral responses to mechanical stimuli were approximately equal in HYPO versus intact female as well as male rats (Figure 1C and 1D). At 24 hours postsurgery, postoperative mechanical hypersensitivity was slightly higher but not statistically significant (lower threshold) in HYPO female versus HYPO male rats $(13.83 \pm 2.7$ for females $v s .19 \pm 2.5$ for male; 3-way ANOVA with sex, rat line and time as factors; $\mathrm{p}=0.15, \mathrm{n}=6$ ). However, removal of pituitary in females and males did not influence the level and time-course of postoperative mechanical hypersensitivity at 1,3 and 7 days post-surgery (Figure 1C and 1D). In summary, incision-induced thermal and mechanical hypersensitivity levels and development time-course were not affected by HYPO in female and male rats.

\section{Ovariectomy and postoperative hypersensitivity}

Since hypophysectomy substantially decreases gonadal hormone

Table 1. Pituitary and gonadal hormones in serum of intact, hypophysectomized, ovariectomized and gonadectomized rats.

\begin{tabular}{|l|c|c|c|}
\hline & Estradiol (pg/ml) & Testosterone (ng/ml) & PRL (ng/ml) \\
\hline Female & $47 \pm 7$ & $0.05 \pm 0.01$ & $75 \pm 8$ \\
\hline Male & $22 \pm 6$ & $7 \pm 2$ & $14 \pm 3$ \\
\hline Hypophysectomized female & $14 \pm 2$ & $\mathrm{NE}$ & $11 \pm 3$ \\
\hline Hypophysectomized male & $12 \pm 3$ & $\mathrm{NE}$ & $8 \pm 2$ \\
\hline Ovariectomized & $13 \pm 4$ & $\mathrm{ND}(<0.01)$ & $9 \pm 2$ \\
\hline Gonadectomized & $17 \pm 4$ & $\mathrm{ND}(<0.01)$ & $10 \pm 3$ \\
\hline
\end{tabular}

$\mathrm{NE}$ - not evaluated; ND - non-detectable levels; $\mathrm{N}=4-6$ 

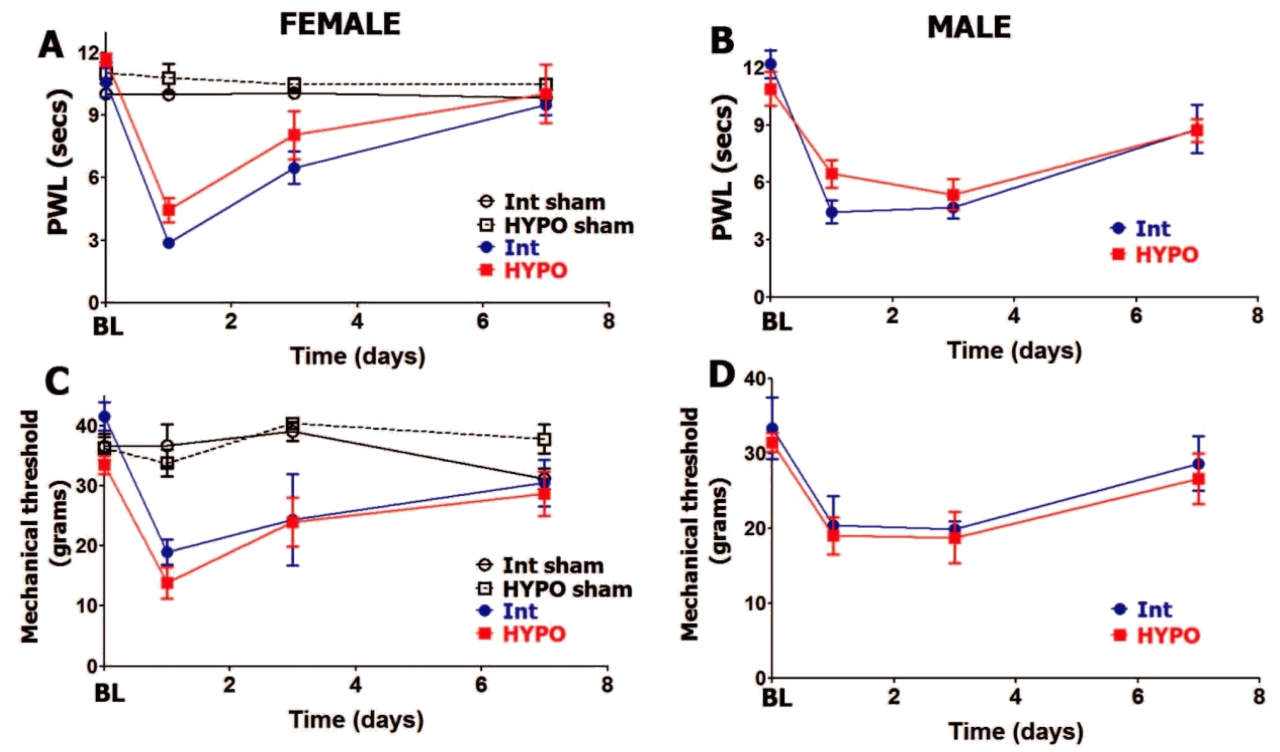

Figure 1.Hypophysectomy and postoperative hypersensitivity in female and male rats.

Incision-induced thermal hypersensitivity in intact (int) and hypophysectomized (HYPO) female (A) and male (B)rats. Baseline (BL) thermal nociception and thermal hypersensitivity are measured as paw withdrawal latency (PWL) in seconds (non-significant; 2 -way ANOVA time and rat lines are factors; $n=5$-7). Incision-induced mechanical hypersensitivity in Int and HYPO female (C) and male(D) rats. BL mechanical nociception and mechanical hypersensitivity are measured as pawwithdrawal threshold in grams (non-significant; 2-way ANOVA time and rat lines are factors; $n=5-7$ ). Post-incision time points are indicated below $\mathrm{X}$-axis. Rat lines and sex are noted. Intact and HYPO female shams are for $\mathrm{n}=5$ (each).

production, we separately evaluated roles of gonad-produced hormones on postoperative hypersensitivity in female and male rats. OVX lowers estradiol levels three-fold and testosterone to levels that are not detectable (Table 1). Besides gonadal hormone, OVX results in reduction of some pituitary hormones, such as serum PRL [35] (Table 1). Baseline (BL) thermal and mechanical nociception was not affected by OVX (Figure 2A and 2B). OVX rats did not differ from intact female rats (in estrous phase) in levels of thermal (Figure 2A) and mechanical (Figure 2B)postoperative hypersensitivity. For both OVX and intact female rats, postoperative hypersensitivity receded to almost preoperated levels at 7 days post-surgery (Figure 2A and 2B).

\section{Gonadectomy and postoperative hypersensitivity}

GDX rats were found to have undetectable amounts of serum total testosterone and a reduction of serum estradiol $(\approx 1.5$ folds) and PRL compared to intact males (Table 1). GDX intervention in male rats did not affect $\mathrm{BL}$ thermal and mechanical nociception (Figure $3 \mathrm{~A}$ and 3B). Incision-induced thermal hypersensitivity lasted 7 days in intact and GDX males, and was statistically insignificantly different at every evaluated post-surgery time point (Figure 3A). Similarly, GDX and intact male rats have almost equal mechanical hypersensitivity and development time-course. Overall, OVX on female and GDX on male rats did not affect level and time-course of postoperative thermal or mechanical hypersensitivity.

\section{Discussion}

Surgical intervention activates the endocrine system [1-3]. This activation is known to affect the HPA axis, altering pituitary and gonadal hormone production after many different surgical procedures [1,6-8]. The roles of pituitary hormones in modulation of postoperative hypersensitivity/pain are unknown. Here, we investigated influence of pituitary hormones on postoperative hypersensitivity levels and development time-courses. Since the disruption of pituitary
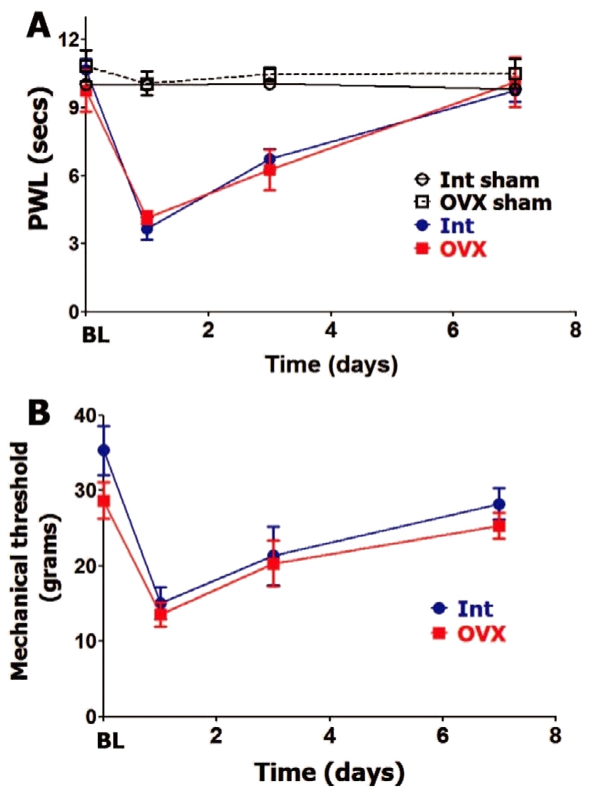

Figure 2. Ovariectomy and postoperative hypersensitivity in female rats.

Incision-induced thermal (A) and mechanical (B) hypersensitivity are evaluated in Int female rats in estrous phase and ovariectomized (OVX) female rats. BL nociception and hypersensitivity are measured as PWL for thermal stimuli and threshold for mechanical stimuli (non-significant; 2-way ANOVA time and rat lines are factors; $n=5$-6). Post-incision time points are indicated below X-axis. Rat lines are noted. Int and OVX shams are for $\mathrm{n}=5$ (each).

hormone production dramatically reduced gonadal hormone levels, we also examined the influence of hormones generated by gonads on postoperative hypersensitivity in female and male rats. Pituitary and gonadal hormone supply were ablated by disconnection or removal of the pituitary (i.e., Hypophysectomy), ovaries (i.e., ovariectomy) 

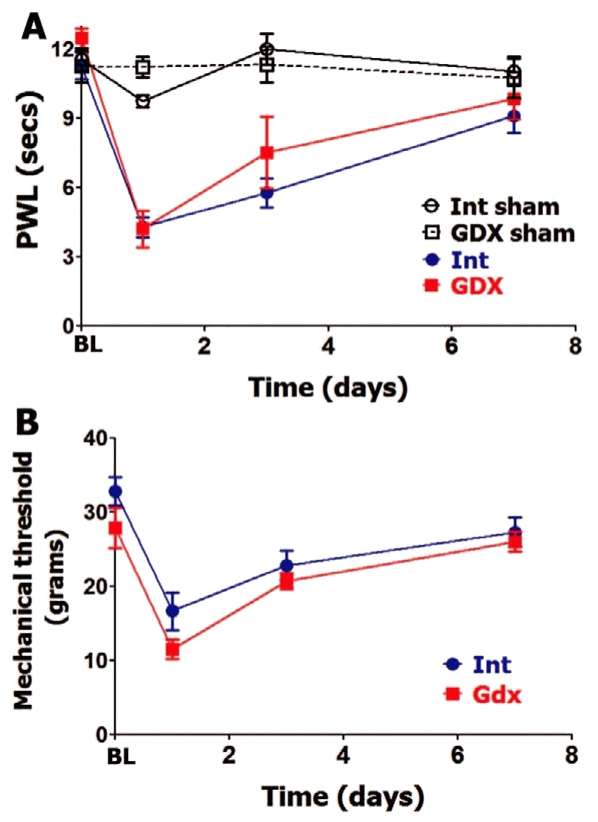

Figure 3. Gonadectomy and postoperative hypersensitivity in male rats.

Incision-induced thermal (A) and mechanical (B) hypersensitivity are evaluated in Int and gonadectomized (GDX) male rats. BL nociception and hypersensitivity are measured as PWL for thermal stimuli and threshold for mechanical stimuli (non-significant; 2-way ANOVA time and rat lines are factors; $n=5-6$ ). Post-incision time points are indicated below X-axis. Rat lines are noted. Int and GDX shams are for $\mathrm{n}=4$ (each).

or testis (i.e.,gonadectomy). Our results indicate that HYPO, OVX and GDX procedures on female and male rats do not significantly influence thresholds and development time-courses of thermal and mechanical postoperative hypersensitivity. HYPO females compared to HYPO males also had statisticallyinsignificant differences in level and development of postoperative hypersensitivity. Finally, as expected $[20,36]$, intact male and female rats have comparable postoperative hypersensitivity throughout 7 post-surgery days; at this time point, postoperative hypersensitivity had declined to almost baseline nociception.

The role of HYPO on pain levels and development dynamics has not been widely studied in different animal pain models or different human pain conditions. Hence, there is no unified theory or known underlying mechanism in regards to the contribution of the pituitary gland to pathological pain/hypersensitivity. Scarce information exists on the influence of pituitary hormones on pain in certain conditions. Clinical studies have provided some information though, as HYPO has traditionally been successfully used to suppress severe pain in some types of cancer [37-41]. It is thought that some supratentorial intracranial lesions, including HYPO, may effectively control chronic but not acute pain in humans [42]. Thus, neural-endocrine circuits for acute pain models could be accounted mostly, if not all, to the sympathetic system [43]. However, this paradigm may not apply to all acute pain models, as HYPO can produce analgesia in formalin-induced tonic pain model [44]. Additionally, HYPO can almost completely abolish the stress-induced analgesia found in some acute pain models [45-47]. Like HYPO, ablation of gonadal hormones affects acute/tonic pain in the formalin model [48]. Overall, effects of ovariectomy and gonadectomy on hypersensitivity levels in acute pain conditions are similar to removal of pituitary. However, circulating gonadal hormones substantially influence responses to systemic morphine [49]. This is understandable since opioids show significant sex-based differences for analgesic efficacy, safety profile and abuse/addiction potential [50-53].

Ablation of pituitary or gonadal hormone supply does not significantly influence postoperative thermal or mechanical hypersensitivity in an acute post-surgery pain model. However, recent reports have shown that surgical procedures can trigger up-regulation of traditional pituitary hormones in extra-pituitary levels at the surgery affected tissues and spinal cord that are in the vicinity of peripheral and central terminals of sensory neurons $[20,54]$.

Gonadal hormones can also be supplied by extra-gonadal sources [55]. Our results imply that despite activation of the HPA axis by surgical interventions, extra-pituitary and extra-gonadal origins of these hormones may play a key role in regulation of postoperative pain. Regulation of extra-pituitary and extra-gonadal hormone production following surgery is a seldom studied area. Nevertheless, this could be important area of research, since certain pituitary and gonadal hormones could be vital contributors in conditions where surgery is accompanied by prolonged stress that strongly influences the timecourse of postoperative hypersensitivity in rodents [56,57].

\section{Acknowledgment}

The authors thank Michael Henry, D.D.S., Ph.D. (Professor, Department of Endodontics, The University of Texas Health Science Center, San Antonio, TX) for setting up and training to acute postoperative pain models in rats (i.e incision model). This work was supported by NIH/NINDS F31 NS082019 (D.P.G.); American Heart Association AHA-44081 (M.J.P); NIH/NIGMS R01 GM112747 (A.N.A.) and School of Dentistry URC pilot project (A.N.A.).

\section{References}

1. Reiner Z, Oresković M, Ribarić K (1987) Endocrine responses to head and neck surgery in men. Acta Otolaryngol 103: 665-668. [Crossref]

2. Anand KJ (1986) The stress response to surgical trauma: from physiological basis to therapeutic implications. Prog Food Nutr Sci 10: 67-132. [Crossref]

3. Minton JP, Dickey RP (1973) Levodopa test to predict response of carcinoma of the breast to surgical ablation of endocrine glands. Surg Gynecol Obstet 136: 971-974. [Crossref]

4. Kehlet H, Dahl JB (2003) Anaesthesia, surgery, and challenges in postoperative recovery. Lancet 362: 1921-1928. [Crossref]

5. Desborough JP (2000) The stress response to trauma and surgery. Br J Anaesth 85 109-117. [Crossref]

6. Noel GL, Suh HK, Stone JG, Frantz AG (1972) Human prolactin and growth hormone release during surgery and other conditions of stress. J Clin Endocrinol Metab 35 840-851. [Crossref]

7. Chernow B, Alexander HR, Smallridge RC, Thompson WR, Cook D, et al. (1987) Hormonal responses to graded surgical stress. Arch Intern Med 147: 1273-1278. [Crossref]

8. Chan V, Wang C, Yeung RT (1978) Pituitary-thyroid responses to surgical stress. Acta Endocrinol (Copenh) 88: 490-498. [Crossref]

9. Chrousos GP (1995) The hypothalamic-pituitary-adrenal axis and immune-mediated inflammation. N Engl J Med 332: 1351-1362. [Crossref]

10. Yardeni IZ, Shavit Y, Bessler H, Mayburd E, Grinevich G, et al. (2007) Comparison of postoperative pain management techniques on endocrine response to surgery: a randomised controlled trial. Int J Surg 5: 239-243. [Crossref]

11. Noreng MF, Jensen P, Tjellden NU (1987)Per- and postoperative changes in the concentration of serum thyreotropin under general anaesthesia, compared to general anaesthesia with epidural analgesia. Acta Anaesthesiol Scand 31: 292-294.

12. Campesi I, Fois M, Franconi F (2012) Sex and gender aspects in anesthetics and pain medication. Handb Exp Pharmacol 214: 265-278. [Crossref]

13. Sakellaris G, Petrakis I, Makatounaki K, Arbiros I, Karkavitsas N, et al. (2004) Effects 
of ropivacaine infiltration on cortisol and prolactin responses to postoperative pain after inguinal hernioraphy in children. J Pediatr Surg 39: 1400-1403. [Crossref]

14. Solak M, Ulusoy H, Sarihan H (2000) Effects of caudal block on cortisol and prolactin responses to postoperative pain in children. Eur J Pediatr Surg 10: 219-223. [Crossref]

15. Tseng YH, Kessler MA, Schuler LA (1997) Regulation of interleukin (IL)-1alpha, IL1beta, and IL-6 expression by growth hormone and prolactin in bovine thymic stromal cells. Mol Cell Endocrinol 128: 117-127. [Crossref]

16. Matera L (1996) Endocrine, paracrine and autocrine actions of prolactin on immune cells. Life Sci 59: 599-614. [Crossref]

17. Woolf CJ, Allchorne A, Safieh-Garabedian B, Poole S (1997) Cytokines, nerve growth factor and inflammatory hyperalgesia: the contribution of tumour necrosis factor alpha. Br J Pharmacol 121: 417-424. [Crossref]

18. Dispersyn G, Sage D, Challet E, Pain L, Touitou Y (2009) Plasma corticosterone in rats is specifically increased at recovery from propofolanesthesia without concomitant rise of plasma acth. Chronobiol Int 26: 697-708. [Crossref]

19. Vijayan E, Krulich L, McCann SM (1978) Catecholaminergic regulation of TSH and growth hormone release in ovariectomized and ovariectomized, steroid-primed rats. Neuroendocrinology 26: 174-185. [Crossref]

20. Patil MJ, Green DP, Henry MA, Akopian AN (2013) Sex-dependent roles of prolactin and prolactin receptor in postoperative pain and hyperalgesia in mice. Neuroscience 253: 132-141. [Crossref]

21. Ozler A, Turgut A, Soydinc HE, Sak ME, Evsen MS, (2013) The biochemical and histologic effects of adnexal torsion and early surgical intervention to unwind detorsion on ovarian reserve: An experimental study. Reprod Sci 20: 1349-1355. [Crossref]

22. Smanik EJ, Mullen KD, Giroski WG, Mccullough AJ (1991) The influence of portacaval anastomosis on gonadal and anterior-pituitary hormones in a rat model standardized for gender, food-intake, and time after surgery. Steroids 56:237-241. [Crossref]

23. Marcondes FK, Bianchi FJ, Tanno AP (2002) Determination of the estrous cycle phases of rats: some helpful considerations. Braz J Biol 62: 609-614. [Crossref]

24. Brennan TJ, Vandermeulen EP, Gebhart GF (1996) Characterization of a rat model of incisional pain. Pain 64: 493-501. [Crossref]

25. Hargreaves K, Dubner R, Brown F, Flores C, Joris J (1988) A new and sensitive method for measuring thermal nociception in cutaneous hyperalgesia. Pain 32: 77-88. [Crossref]

26. Nagy E, Berczi I (1991) Hypophysectomized rats depend on residual prolactin for survival. Endocrinology 128: 2776-2784. [Crossref]

27. Andersson K, Fuxe K, Eneroth P, Nyberg F, Roos P (1981) Rat prolactin and hypothalamic catecholamine nerve-terminal systems - evidence for rapid and discrete increases in dopamine and noradrenaline turnover in the hypophysectomized male-rat. Eur J Pharmacol 76: 261-265. [Crossref]

28. Ben-Jonathan N, Mershon JL, Allen DL, Steinmetz RW (1996) Extrapituitary prolactin: distribution, regulation, functions, and clinical aspects. Endocr Rev 17: 639669. [Crossref]

29. DeVito WJ (1989) Immunoreactive prolactin in the hypothalamus and cerebrospinal fluid of male and female rats. Neuroendocrinology 50: 182-186. [Crossref]

30. Bogovich K (1992) Follicle-stimulating hormone plays a role in the induction of ovarian follicular cysts in hypophysectomized rats. Biol Reprod 47: 149-161. [Crossref]

31. Rudenstein RS, Bigdeli H, McDonald MH, Snyder PJ (1979) Administration of gonadal steroids to the castrated male rat prevents a decrease in the release of gonadotropinreleasing hormone from the incubated hypothalamus. J Clin Invest 63: 262-267. [Crossref]

32. Strobl FJ, Levine JE (1988)Estrogen inhibits luteinizing hormone (lh), but not folliclestimulating hormone secretion in hypophysectomized pituitary-grafted rats receiving pulsatile lh-releasing hormone infusions. Endocrinology 123: 622-630. [Crossref]

33. Teerds KJ, Closset J, Rommerts FF, de Rooij DG, Stocco DM, et al. (1989) Effects of pure FSH and LH preparations on the number and function of Leydig cells in immature hypophysectomized rats. $J$ Endocrinol 120: 97-106. [Crossref]

34. Yang J, Yang Y, Chen JM, Liu WY, Lin BC (2008) Investigating the role of the hypothalamic supraoptic nucleus in nociception in the rat. Life Sci 82: 166-173. [Crossref]
35. AmenomorY, Chen CL, Meites J (1970) Serum prolactin levels in rats during different reproductive states. Endocrinology 86: 506-510. [Crossref]

36. Banik RK, Woo YC, Park SS, Brennan TJ (2006) Strain and sex influence on pain sensitivity after plantar incision in the mouse. Anesthesiology 105: 1246-1253. [Crossref]

37. Silverberg GD (1977) Hypophysectomy in the treatment of disseminated prostate carcinoma. Cancer 39: 1727-1731. [Crossref]

38. Tindall GT, Ambrose SS, Christy JH (1975)Hypophysectomy in the treatment of disseminated carcinoma of the breast and prostate gland. J Med Assoc Ga 64: 69-74. [Crossref]

39. Katz J, Levin AB (1977) Treatment of diffuse metastatic cancer pain by instillation of alcohol into the sellaturcica. Anesthesiology 46: 115-121. [Crossref]

40. Fitzpatrick JM, Gardiner RA, Williams JP, Riddle PR, O’Donoghue EP (1980) Pituitary ablation in the relief of pain in advanced prostatic carcinoma. Br J Urol 52: 301-304. [Crossref]

41. Brodkey JS, Pearson OH, Manni A (1978) Hypophysectomy for relief of bone pain in breast cancer. N Engl J Med 299: 1016. [Crossref]

42. Sweet WH (1980) Central mechanisms of chronic pain (neuralgias and certain other neurogenic pain). Res PublAssoc Res Nerv Ment Dis 58: 287-303. [Crossref]

43. Miao FJP, Levine JD (1999) Neural and endocrine mechanisms mediating noxious stimulus-induced inhibition of bradykinin plasma extravasation in the rat. $J$ Pharmacol Exp Ther 291: 1028-1037. [Crossref]

44. Lariviere WR, Fuchs PN, Melzack R (1995) Hypophysectomy produces analgesia and paraventricular lesions have no effect on formalin-induced pain. Exp Neurol 135: 7479. [Crossref]

45. Bodnar RJ, Glusman M, Brutus M, Spiaggia A, Kelly DD (1979) Analgesia induced by cold-water stress: Attenuation following hypophysectomy. Physiol Behav 23:53-62. [Crossref]

46. Millan MJ, Przew§, ocki R, HerzA(1980) Anon-beta-endorphinergicadenohypophysea mechanism is essential for an analgetic response to stress. Pain 8: 343-353. [Crossref]

47. MacLennan AJ, Drugan RC, Hyson RL, Maier SF, Madden J 4th, et al. (1982) Corticosterone: a critical factor in an opioid form of stress-induced analgesia. Science 215: 1530-1532. [Crossref]

48. Ceccarelli I, Fiorenzani P, Massafra C, Aloisi AM (2006) Repeated nociceptive stimulation induces different behavioral and neuronal responses in intact and gonadectomized female rats. Brain Res 1106: 142-149. [Crossref]

49. Cataldo G, LovricJ, Chen CC, Pytte CL, Bodnar RJ (2010) Ventromedial and medial preoptic hypothalamic ibotenic acid lesions potentiate systemic morphine analgesia in female, but not male rats. Behav Brain Res 214:301-316. [Crossref]

50. Aubrun F, Salvi N, Coriat P, Riou B (2005) Sex- and age-related differences in morphine requirements for postoperative pain relief. Anesthesiology 103: 156-160. [Crossref]

51. Schnabel A, Poepping DM, Gerss J, Zahn PK, Pogatzki-Zahn EM (2012) Sex-related differences of patient-controlled epidural analgesia for postoperative pain. Pain 153: 238-244. [Crossref]

52. Bartley EJ, Fillingim RB (2013) Sex differences in pain: a brief review of clinical and experimental findings. Br J Anaesth 111: 52-58. [Crossref]

53. Lee CWS, Ho IK (2013) Sex differences in opioid analgesia and addiction: Interactions among opioid receptors and estrogen receptors. Mol Pain 9. [Crossref]

54. Scotland PE, Patil M, Belugin S, Henry MA, Goffin V (2011) Endogenous prolactin generated during peripheral inflammation contributes to thermal hyperalgesia. Eur $J$ Neurosci 34:745-754.

55. Burger HG (2001) Physiological principles of endocrine replacement: estrogen. Horm Res 56 Suppl 1: 82-85. [Crossref]

56. Li C, Yang Y, Liu S, Fang H, Zhang Y, et al. (2014) Stress induces pain transition by potentiation of AMPA receptor phosphorylation. J Neurosci 34: 13737-13746. [Crossref]

57. Liu Y, Hou B, Zhang W, Sun YE, Li L, et al. (2015) The activation of spinal astrocytes contributes to preoperative anxiety-induced persistent post-operative pain in a rat model of incisional pain. Eur J Pain 19: 733-740. [Crossref]

Copyright: ( 2016 Akopian AN. This is an open-access article distributed under the terms of the Creative Commons Attribution License, which permits unrestricted use, distribution, and reproduction in any medium, provided the original author and source are credited. 